Background The Safe Children Community Deutschlandsberg was expanded to the Safe Children Community of Southwest Styria which now comprises three districts. Initiation, development and implementation of successful projects and programs have furthered the reduction of child injury rates. Additionally, evaluation of programs, measures, and injury data was carried out to determine whether the efforts achieved the desired results.

Methods The steering committees of each district comprising all relevant representatives established working groups for categories such as safety in traffic, at home, in school and preschool, during sports, and during leisure time, as well as injury surveillance. A variety of child-safety activities in different settings were developed, involving as many organisations, institutions, schools and professional groups as possible, as well as local media.

Results Data surveillance demonstrated a reduction in child injuries. The relative injury rate of the Safe Children region decreased from 216/1000 in 2012 to 201/1000 in 2014. The pilot district Deutschlandsberg (designated in 2011 as the first Safe Children Community) was able to reduce the child injury rate from 195 in 2012 to 180 in 2014.

Conclusions Motivating a community to carry out injury-prevention initiatives is much easier when the focus is on children. It is also very useful to have champions from all public and private sectors and areas on the steering committees and in the working groups. In addition, it is helpful if a structure of participation is supported by the top-down-principle in the public sector. Despite all the internal motivation, a Safe Children Community has to be driven by external input and expertise. In order to develop and realise projects and receive the attention of Safe Kids Austria as a coordinating body, it is important to have the financial support of the Styrian Government and the districts themselves.

\section{KENTUCKY SAFE COMMUNITIES: A MODEL FOR RECRUITMENT AND GROWTH, 2012-2017}

${ }^{1}$ Genia McKee, ${ }^{2}$ Carrie Nie. ${ }^{1}$ University of Kentucky, Kentucky, USA; ${ }^{2}$ National Safety Council, Safe Communities America, USA

\subsection{6/injuryprev-2016-042156.444}

Background After several years of decreasing injury rates, in 2010, there began an upward injury fatality trend in Kentucky fueled largely by increases in accidental drug overdose and suicide. In 2012, Kentucky's age-adjusted injury fatality rate had increased from 76.1 in 2010 to 81.8 per 100,000 population.

Description of the problem The state has 120 counties and a total population of 4.4 million. Numerous agencies are charged with injury prevention, however there is a lack of coordination and local injury data, making prevention efforts fragmented and inefficient. We adopted the Safe Communities model as a way to address rising injury rates. The Safe Community model originated with the World Health Organisation's Collaborating Centre on Community Safety Promotion's Karolinska Institute.

Results In 2012, the Kentucky Injury Prevention and Resource Centre (KIPRC), Kentucky's lead injury prevention agency, became a Safe Community Affiliate Support Centre and entered into a partnership with the National Safety Council (NSC) and Safe Communities America with the following five year goals: (1) half the population of the state living within a Safe Community, (2) assist with local prevention planning and, (3) develop local data reports. As of July 2015, there are 8 communities certified or in process, holding nearly $40 \%$ of the state's population, and injury data reports are available for all counties.
Conclusions The Safe Communities approach has been shown to be effective in saving lives and reducing costs. A recent NSC study showed that after 10 years of rising injuries and injury rates in one community, the decision to seek Safe Community accreditation was followed by a 2 -year decline in injury hospitalizations. In those two years, the study showed that nearly 300 hospitalizations may have been prevented, saving the community over $\$ 14$ million in health care costs.

\section{5 "STRENGTHENING HEALTH SAVING"}

1,2Leonor Leinecker, ${ }^{1}$ Nadia Rivera Leinecker, ${ }^{1}$ Ricardo Slavusky, ${ }^{2}$ Augusto Ittig, ${ }^{2}$ Laura Flores. ${ }^{1}$ University Nacional De Jujuy, Jujuy, Argentina; ${ }^{2}$ Secretaria Community Protection, Ministry of Government of Jujuy, Jujuy, Argentina

\subsection{6/injuryprev-2016-042156.445}

Background The province of Jujuy is located in a seismic zone with increasing activity. It is essential that your people know how to act in emergencies and know first-aid; key then is to teach and strengthen the community first responders.

Methods courses of theoretical and practical training in medical first aid are made: for university students and representatives of NGOs to increase the number of "Health Lifeguards: trained to train" that expand the coverage and call this training to all the population of the Province of Jujuy. Courses are taught from the race for Health Educator, Faculty of humanities and social sciences. They have zero cost to those who perform and is planned for 1200 graduation trainers, which will allow the creation of 240 training teams for training gives coverage to the whole province of Jujuy. The political-economic framework is guaranteed by agreements concluded between the National University of Jujuy and the Secretariat of the Community Protection of the Ministry of Government of the Province of Jujuy .

Results In 2014 certified 235 university students and NGO representatives as "Lifeguard Health trained to train" in 2015 training is extended to members of social and sporting institutions, neighbourhood and social organisations and members of non-formal education, with 456 students for certified "Lifeguard Health: trained to train" strengthening Courses are conducted in "First responder" to police, firefighters and civil protection and first responders, granting 95 certifications.

Conclusions The general population and in particular the first respondent properly trained how to act in an emergency, helps reduce fatal consequences and the consequences of the same, reducing YPLL injuries and disabilities.

\section{HEALTHY NIGHTLIFE: ELIMINATE RISK, PROMOTE PROTECTIVE FACTORS \& CITY RESILIENCE (COIMBRA, PORTUGAL)}

${ }^{1}$ João Redondo, ${ }^{2}$ Fernando Mendes, ${ }^{3}$ Isabel Fonseca, ${ }^{4}$ Jorge Alves, ${ }^{5}$ Paulo Anjos, ${ }^{6}$ Irma Brito, ${ }^{7}$ Henrique Armindo, ${ }^{8}$ António Monteiro, ${ }^{9}$ Laura Diogo, ${ }^{10}$ Cristina Baptista, ${ }^{1}$ Paulo Simões, ${ }^{1}$ Filipa Sola, ${ }^{1}$ Alexandre Fernandes. ${ }^{1}$ Centre for Prevention and Treatment of Psychological Trauma (CPTTP), Department of Psychiatry, Coimbra University Hospital Centre, CHUC, Portugal; ' ${ }^{2}$ European Institute of Studies on Prevention (IREFREA, Portugal); ${ }^{3}$ Emergency Department, CHUC, Portugal; ${ }^{4}$ Municipality of Coimbra, Portugal; ${ }^{5}$ Associação Existências, Portugal; ${ }^{6}$ Higher School of Nursing, Coimbra, Portugal; ${ }^{7}$ National Guard (GNR), Coimbra, Portugal; ${ }^{8}$ Public Security Police (PSP) of Coimbra, Portugal; ${ }^{9}$ Coimbra Group of Schools West, Portugal; ${ }^{10}$ Coimbra Group of Schools Central, Portugal

10.1136/injuryprev-2016-042156.446 